influence of ice. Her general condition almost immediately began to improve. Her stomach settled, and she was soon able to be put upon a liberal diet, gaining as much as ten pounds a week. After the third day I irrigated right through into the bladder with formalin, 1:2000, and peroxide diluted one-third, for three and one-half weeks. On removal of the tubes, the wound healed almost in a night, and within a week nothing remained to be dressed. In seven weeks after operation she was on her feet, and walked out of the hospital on the fiftieth day.

The tenderness of the kidney, evidently due as much to congestion as to infection, gradually subsided; the bladder irritation disappeared and the amount of pus in the urine diminished to a very small quantity, possibly coming from the opposite kidney. A culture from the wound, one and a half weeks after the operation, showed colon bacilli still present, but none were found after the third week, which determined me in removing the tubes and allowing the wound to heal.

The interest in this case lies in the general systemic intoxication produced by this infection, and the rapid response of the system to the thorough douching of the pelvis of the kidney and ureters with the antiseptic solution. The indications for the nephrotomy were clear, and the great benefit derived from the through-and-through flushing of the infected tract, according to well-founded surgical principles, bespeaks for this radical method a more frequent application.

\title{
GUNSHOT WOUNDS OF THE URETER; TWO CASES OF URETEROVESICAL ANASTOMOSIS. ${ }^{1}$
}

\section{By George Tully Vaughan, M.D.,}

\begin{abstract}
ABSIGTANT SURGEON-GENERAI, UNITED STATES PUBLTC FEALTH AND MARINE GOSPITAL
\end{abstract} SERVICE; PROFESSOF OF SURGERY, GEORGETOWN UNIVERSITY.

GUNSHOT wounds of the ureter are so exceedingly rare that I feel it to be my duty to report the case which fell under my care. In the history of surgery, so far as I have been able to ascertain, there has been recorded only one authenticated case of gunshot wound of the ureter, and that was the case of the archbishop of Paris, who was shot June 29, 1848. The ball entered the right lumbar region close to the spine. There was great depression, pale, anxious countenance, nausea, vomiting, intense pairl in back and in the course of the sciatic nerves, and paralysis of the lower limbs. Urine flowed from the wound in great quantities and there was none in the bladder. An attempt to remove the ball was made

\footnotetext{
1 Read at the Thirteenth Session of the Assoclation of Military Surgeons of the United States.
} 
without success and death occurred eighteen hours after the injury. A necropsy showed that the ball had passed through the third lumbar vertebra dividing the cauda equina just below its origin and the left ureter close to the pelvis of the kidney and lodged in the psoas muscle.

The doubtful case of Rayer reported by Hennen seems to have been a gunshot wound of the kidney. My case was as follows:

CASE I.-C. T., colored, male, aged thirty years, laborer, was admitted to the Emergency Hospital on account of an abdominal fistula which had followed a gunshot wound of the abdomen received October 3, 1903. The ball, a 0.32 , entered about one inch to the inner side of the right anterior superior spinous process of the ilium and just below Poupart's ligament and lodged under the skin behind in the median line, having perforated or notched the fourth bone of the sacrum, whence it was removed.

A purulent discharge with symptoms of peritonitis followed and on October 11, my colleague, Dr. W. P. Carr, suspecting perforation of the bladder or bowel did an exploratory laparotomy in the median line. Numerous adhesions were found but no wound of the abdominal viscera. 'The wound was closed, with drainage in front, and in a week thcre was a purulent discharge in front through the opening for drainage and behind at the point of exit of the bullet, so daily through-and-through irrigation was used. The patient gradually improved, the discharge became thinner and looked almost as clear as water. On examination it was found to contain a little pus and a trace of urea. December 3, 1903, the patient was discharged recovered, with the exception of the fistula in front.

He was readmitted March 15, 1904 for the purpose of getting cured of the fistula, which had continued to discharge since leaving the hospital and kept his clothing constantly wet. A slight discharge also came from the posterior wound. The patient suffered no pain, ate and slept well, was well nourished and able to work. He voided from the bladder about 22 ounces of urine in twentyfour hours and from the fistula, judging from the amount collected for several hours, by means of a tube in the fistula, 2 ounces an hour or 48 ounces in twenty-four hours.

Examination of urine from the bladder gave the following result: reaction, acid; specific gravity, 1022; urea, 6 grains to the ounce; no albumin or sugar; $a$ few pus cells. Fluid from the fistula appeared thin and slightly milky in color, reaction faintly acid; specific gravity, 1010; urea 1 grain to the ounce; pus cells abundant; a trace of albumin present. A probe could be passed into the fistula in front to the depth of four and three-quarters inches when it was arrested by a hard body, probably bone. Through the posterior opening the probe could be inserted to a distance of a little over two inches. 
A diagnosis of wound of the right ureter was made and on March 19 th the patient was operated on. The abdomen was opened along the outer border of the right rectus muscle and afterward the rectus was divided transversely just below the navel. The probe inserted through the anterior fistula was used as a guide but the operation was tedious and difficult on account of the numerous and strong adhesions of the intestines with one another and with the pelvic walls. 'The right ureter was finally exposed. It was found dilated to at least twice its normal size and was traced into a mass of unusually dense adhesions in the bottom of the pelvis. In attempting to free the ureter it was broken off at the location of the fistula as was shown by the appearance of the proximal end.

Nature was making a brave attempt to close the fistula, and incidentally the ureter itself, as at the site of the fistula the ureter was much contracted in calibre-being not larger than one-fourth or one-fiftl of the dilated portion above. The result of this contraction was not only dilatation of the ureter but also probably damage to the kidney, as shown by the small percentage of urea found in the urime from the fistula. Sewing together the ends of the ureter (uretero-ureteral anastomosis) would have been almost impossible even if desirable, at this point, so ureterovesical anastomosis was decided upon. The bladder was opened in front and a small oblique opening was made through its posterior wall on the right side at a point considerably above the normal opening of the ureter. The end of the ureter was then split into two flaps about one-eighth of an inch long and drawn into the bladder by means of forceps introduced through the anterior and posterior openings. 'The flaps were spread open and stitched to the inside of the bladder by sutures whose knots were tied on the peritoneal surface of the bladder. The ureter was also sewed to the posterior surface of the bladder at its point of entrance. Very fine silk sutures were used. The anterior wound in the bladder was closed by two rows of continuous sutures-using first, catgut through all the coats, and second, silk, omitting the mucous coat and inverting the first row. The ends of the rectus muscle were united witl heavy catgut, the longitudinal wound was closed with through-and-through silkwormgut interrupted sutures and continuous catgut for the peritoneum and sheath of the rectus. No drainage for the peritoneal cavity, but a small piece of gauze was left projecting from the space in front of the bladder. A catlieter was kept in the urethra several days to prevent distention of the bladder, but there was slight escape of urine from the anterior wound for a few days. The patient was discharged recovered April 19th. The urine was measured several times before the patient was discharged and was variable-runniug from 32 to 84 ounces in the twenty-four hours. April 17th Dr. F. R. Hagner reported as the result of a cystoscopic examination that the bladder mucosa was normal. The new open- 
ing of the right ureter was seen as a small papillary mass from which urine flowed. A catheter was inserted into the old (normal) opening of the right ureter for about one and one-half inches beyond which it would not go. The scar in the front wall of the bladder was smooth.

The patient was again seen June 15th, about three months after the operation, when he appeared to be in perfect health.

CASE II. Cancer of the rectum; inguinal colostomy; later excision of rectum and part of colon; right ureter divided; ureterovesical anastomosis.-Mrs. E. T., white, aged forty-seven years; was operated on June 8, 1903, an inguinal colostomy being done on the left side, on account of ulceration of the rectum which had existed about a year and resisted all treatment. The patient's health improved after this operation and she gained in weight but continued to discharge pus and blood, so it was decided to remove the diseased rectum. March 14, 1904 this was done through the posterior wall of the vagina, but the disease was found to extend so high up the bowel, that the abdomen had to be opened and all of the rectum from just above the sphincter up to and including a portion of the sigmoid flexure was removed. In doing this the right ureter was accidentally severed near the bladder. The proximal'end was split and sewed into the bladder exactly as in the former case.

There was no leakage so far as known either from ureter or bladder, and the patient made a good recovery and was discharged April 29, 1904.

Conservative surgery of the ureter may be said to date from the year 1877, when the first ureterovesical anastomosis was done by Tauffer. Previous to that time division of the ureter was usually treated by removal of the corresponding kidney, and even as late as 1893 we find Hermann Thompson stating that complete cure in lesions of the ureter is to be obtained only by removal of the kidney. He condemns grafting into the bladder or intestine as methods not to be recommended. Yet in the same year, sixteen years after Tauffer's case, we find the second successful ureterovesical anastomosis done by Novaro.

The next year, 1894, F. Westermark performed the operation under the impression that his was the first successful case in the human being. Since then the enormous increase in the amount of abdominal and especially pelvic surgery has provided numerous occasions for the operation so that by 1903 Bovée had collected 111 cases of ureterovesical anastomosis, with seven deaths.

This operation is indicated whenever the lower part of the ureter has been divided or resected and the proximal end is long enough to reach the bladder. I believe it is to be preferred to any of the methods of uretero-ureteral union which have been suggested or practised for the following reasons given by Baldy: 
(1) It is much easier to perform; (2) it is less likely to be followed by stricture, and (3) in case a stricture does form it is more accessible and easier to treat.

\title{
REFERENCES.
}

Tauffer. Deutsche Medicinische Wochenschrif, 1877, No. 37, p. 438.

Tuffler, M. Archives générales de médecine, Paris, 1884, tome i. pp. 335-360.

McArthur. Medical and Surgical Reporter, Philadelphia, 1889, p. 225.

Thompson, Hermann. Zeitschrift f. Geburtshülfe und Gynäk., Stuttgart, 1898, Bd xxil. p. 173.

Van Hook, W. Journal of the American Medical Association, 1893, vol. $8 x i$. pp. 911, 965.

Jaldy, J. M. American Gynecological and Obstetrical Journal, New York, 1894, vol. v. p.489.

King, F. Ibid., p. 495.

Knotz, I. Präger medicinische Wochenschrift, 1895, Bd. xx. p. 489.

Krause, F, Centralblatt f. Chirurgie, Leipzig, 1805, Bd. $x \times$ ii. p. 220.

Reed, R. H. Columbus Medical Journal, 1805. vol, Xv. p. 492.

Glantenay, L. Chirurgie de l'Uretére, Paris, $1895,8^{\circ}$.

Westermark, F. Zentralblatt f. Gynäkologie, Leipzig, 1895, Bd. xix. p. 184.

Sutton, J. B. London Lancet, 1896, vol. 1. p. 1275.

Amann, J. A. Zentralblatt f. Gynäkologie, Leipzig, 1897, Bd. xxi.

Mikule, Oswald. Ein Beiträg zur Chirurgie der Ureterverletzungen, $8^{\circ}$, Breslau, 1897.

Baldwin. J. F. Philadelphia Medical Journal, November 26, 1898.

Fith, R. Zentralblatt f. Gynäkologie, Leipzig-Bonn, 1898, p. 729.

Morris, H. Edinburgh Medical Journal, 1898, n. s., vol. iii. pp. 11-32.

Macdonald, J. W. Medical Di̊l, Minneapolis, January, 1901.

Bovee, J. W. Annals of Surgery, August, 1900; Amer. Jour. Obstetrics, 1904, vol. xlix. No. 6.

\section{SCABIES IN THE UNITED STATES OF AMERICA AND CANADA.}

\author{
By James Nevins Hyde, M.D., \\ PROFESSOR OF DISEASES OF THE SKIN, RUSH MEDICAL COLLEGE, CHzCAGO.
}

Scabies is a disease assignable to the category of those which have been known since the earliest periods of antiquity. The contention that it is included with those designated under the title "Zaarath" in the Hebrew scriptures-a term which in the English translation of the Books of Kings and Leviticus has been rendered "leprosy"--is at least significant of a belief respecting its prevalence at an early period of the world's history. The literature which has accumulated on the subject of both the symptoms of its invasion of the human family and on the absurd errors which have been committed respecting its nature and effects is voluminous. Since the day when St. Hildegarde first unmistakably referred to the acarus as its effective cause, and Bonomo and Cestoni, in 1787, presented their detailed description of the itch-mite, traversing the epoch when Hahnemann set forth his doctrines respecting the existence of "internal itch," as far as the hither side of the middle of the last century, when even distinguished physicians in France still doubted its origin in the encroachments of an animal parasite, the essays which have multiplied on the theme have been well-nigh innumerable.

Once the exact nature of the disorder established, its literature naturally contracted within channels. Volume One, for example, 